\title{
Article \\ A Randomized Controlled Trial Protocol to Test the Efficacy of a Dual-Task Multicomponent Exercise Program vs. a Simple Program on Cognitive and Fitness Performance in Elderly People
}

\author{
Juan Antonio Párraga-Montilla ${ }^{1}\left(\mathbb{D}\right.$, Agustín Aibar-Almazán ${ }^{2} \mathbb{D}$, José Carlos Cabrera-Linares ${ }^{1, *(\mathbb{D})}$, \\ Emilio Lozano-Aguilera ${ }^{3}$, Víctor Serrano Huete ${ }^{4}$, María Dolores Escarabajal Arrieta ${ }^{5}$ \\ and Pedro Ángel Latorre-Román ${ }^{1}$ (D)
}

check for updates

Citation: Párraga-Montilla, J.A.; Aibar-Almazán, A.; Cabrera-Linares, J.C.; Lozano-Aguilera, E.; Serrano Huete, V.; Escarabajal Arrieta, M.D.; Latorre-Román, P.Á. A Randomized Controlled Trial Protocol to Test the Efficacy of a Dual-Task

Multicomponent Exercise Program vs. a Simple Program on Cognitive and Fitness Performance in Elderly People. Int. J. Environ. Res. Public Health 2021, 18, 6507. https:// doi.org/10.3390/ijerph18126507

Academic Editor: Paul B. Tchounwou

Received: 9 May 2021

Accepted: 11 June 2021

Published: 16 June 2021

Publisher's Note: MDPI stays neutral with regard to jurisdictional claims in published maps and institutional affiliations.

Copyright: (C) 2021 by the authors. Licensee MDPI, Basel, Switzerland This article is an open access article distributed under the terms and conditions of the Creative Commons Attribution (CC BY) license (https:// creativecommons.org/licenses/by/ $4.0 /)$
1 Department of Musical, Plastic and Corporal Expression, Faculty of Humanities and Educational Sciences, University of Jaén, 23071 Jaén, Spain; jparraga@ujaen.es (J.A.P.-M.); platorre@ujaen.es (P.Á.L.-R.)

2 Department of Health Sciences, Faculty of Health Sciences, University of Jaén, 23071 Jaén, Spain; aaibar@ujaen.es

3 Department of Statistics and Operations Research, Faculty of Social and Legal Sciences, University of Jaén, 23071 Jaén, Spain; elozano@ujaen.es

4 Faculty of Humanities and Social Sciences, International University Isabel I, 09003 Burgos, Spain; victor.serrano@ui1.es

5 Department of Psychology, Faculty of Humanities and Educational Sciences, University of Jaén, 23071 Jaén, Spain; descara@ujaen.es

* Correspondence: jccabrer@ujaen.es; Tel.: +34-953-212-490

Abstract: Background: The necessity of improve the life quality in elderly people is well-known. The aim of this study was to determine the effects of physical and cognitive training programs, as well as their combination on the cognitive functions and physical capacities in women over 80 years old. Methods: Forty-three women took part in this study ( $80.86 \pm 5.03$ years). They were divided into four groups (three experimental groups and one control group). Experimental group 1 performed cognitive training. Experimental group 2 did physical-cognitive training, and Experimental Group 3 accomplished physical training. All of training programs had duration of eight weeks (five sessions of 60 min per week). We measured cognitive variables with the Stroop test, D2 test, and Trail Making test. Physical variables were measured with handgrip strength, Minute Step Test, and visual-acoustic reaction time. Results. Control group reduces his physical and cognitive capacities, while the three experimental groups increase these capacities. We found a strong correlation between the increase of physical and cognitive capacities. Conclusion: Eight weeks of training physical, cognitive or mixed, increased physical and cognitive functions of elderly people which may reduce the negative effects of the aging process.

Keywords: physical training; cognitive training; elderly people

\section{Introduction}

Physical activity and cognitive activity are aspects of the well-being of elderly people and are associated with health, morbidity, and mortality [1,2]. The relationship between physical and cognitive activity has been studied [3]. Recently, there has been renewed interest in physical activity associated with increased brain volume and its impact on cognitive function, which is reduced in old age as a natural aging process [4]. Therefore, it is important to focus on motor task exercises that demand attention and involve physical and cognitive capacity simultaneously (dual task). It can be a novel indicator for the detection of physical and cognitive frailty in elderly [5]. The dual-task (DT) paradigm is a relatively new method that involves the performance of two different tasks simultaneously. It was first used in psychological studies in the middle of the 1980s. The DT paradigm was 
then used by health professionals to assess and train elderly people as a secondary task, after walking [6].

Walking performance is considered a strong biomarker of health. In addition, walking is an automatic process in healthy adults. Nevertheless, this automatism decreases as age increase [7]. The DT paradigm detects some gait issues and cognitive deficits which are common in the elderly. This problem cannot be detected if we assess the gait of elderly people with a single task [8]. Consequently, DT can help to decrease deterioration in the elderly [9]. In addition, it can reverse or delay the onset of cognitive deficits [10], thus it is an important component of cognitive protection [11].

Physical activity has a positive effect on the cognitive reserve capacity of the brain, decreasing the effects of aging and the risk of developing neurological diseases and dementia [12]. Specifically, it can improve execution capacity and speed of information processing [13].

Increasing aerobic capacity and blood flow in the brain results in improvements in the use of oxygen and glucose in the brain, greater stimulation of neurogenesis, and an increase in synaptic interconnections [14]. Likewise, Bliss et al. [15] concluded that there is enough evidence that aerobic training can improve cognitive blood flow. Moreover, Nagamatsu et al. [16] found an association between physical fitness and cognitive performance in women aged 70-80 years and concluded that aerobic training has an influence on the improvement of verbal and spatial memory and verbal-auditory learning. Similarly, Liu-Ambrose et al. [17] found that aerobic and resistance programs enhanced selective attention, conflict resolution, and processing speed. Likewise, Vaughan et al. [18] showed that a multicomponent strength, aerobic, and motor aptitude training program had a beneficial effect on physical and cognitive performance tests as well as on peripheral blood concentrations of brain-derived neurotrophic factor (BDNF) which is a protein associated with nerve growth factor. In addition, aerobic exercise counteracts neurological decreases that are associated with cognitive factors and physical impairments [19].

Keating et al. [20] showed that a resistance training program focused on the lower body produces significant improvements in balance and gait in this population range, in addition, these authors found an increase in strength levels at this age is associated with a higher quality of life and less dependency during the aging process. In relation to a training program (aerobic or resistance), aerobic training has a positive effect on the quality of life in elderly adults since it reduces the risk of cardiovascular diseases and improves functional parameters [21].

On the whole, greater upper-body strength is considered an indicator of general vitality and a predictor of cognitive functioning, and consequently disability and mortality [1]. Taekema et al. [22] suggest that elderly adults having less grip strength correlates with lower scores in functional, psychological, and social health, predicting an accelerated decrease in the activities of daily living and cognition. In addition, a decrease in strength level correlates with an increased dependence with regard to activities of daily living [15,23], cognitive impairment [23,24], and mortality [25,26]. Reaching 65 years of age is a turning point for these capacities as there is an association between handgrip strength and cognitive performance [1]. At advanced ages, physical performance is compromised in numerous cognitive tasks that require a variety of perceptual and cognitive processes, slowing execution speed $[27,28]$. Therefore, the time-reaction is considered an indicator of nervous system performance that is seriously affected in elderly people $[29,30]$.

Therefore, it is necessary to analyze the effects of the combined training programs on the physical capacities and the cognitive function of sedentary elderly people. In addition, it is important to define the criteria for prescribing a cognitive training program, a physical training program, or both. Thereby, the aim of this study was to determine the effects of physical and cognitive training programs, as well as their combination on the cognitive functions and physical capacities in women over 80 years old. Our initial hypothesis deals with the fact that a combined program of physical and cognitive exercise based on DT 
paradigm would have a greater effect on physical and cognitive abilities in elderly adults than when cognitive or physical training is performed independently.

\section{Materials and Methods}

\subsection{Participants}

Forty-three women $\left(80.86 \pm 5.03\right.$ years; BMI $\left.=24.39 \pm 2.44 \mathrm{~kg} / \mathrm{m}^{2}\right)$ participated in this study (Table 1). The participants attended a "day center" from Monday to Friday to carry out different activities. In Spain, a "day center" is a place which elderly people attend during a certain number of hours each day (morning or afternoon) to perform different activities directed by professionals from different fields (such as physiotherapists, psychologists, and physical trainers) aimed at improving their physical and cognitive abilities. The researchers moved to the day center to conduct the training session and to evaluate the participants (pre and post-test).

Table 1. Age, and anthropometric characteristics of the participants.

\begin{tabular}{ccccccc}
\hline & $\begin{array}{c}\text { TOTAL } \\
\boldsymbol{n}=\mathbf{4 3} \\
\text { Mean (SD) }\end{array}$ & $\begin{array}{c}\text { CG } \\
\boldsymbol{n}=\mathbf{1 1} \\
\text { Mean (SD) }\end{array}$ & $\begin{array}{c}\text { EG1 } \\
\boldsymbol{n}=\mathbf{1 0} \\
\text { Mean (SD) }\end{array}$ & $\begin{array}{c}\text { EG2 } \\
\boldsymbol{n}=\mathbf{1 0} \\
\text { Mean (SD) }\end{array}$ & $\begin{array}{c}\text { EG3 } \\
\boldsymbol{n} \text { (2) } \\
\text { Mean (SD) }\end{array}$ & $\boldsymbol{p}$ Value \\
\hline Age (years) & 80.86 & 78.54 & 82.00 & 82.70 & 80.50 & \\
& $(5.03)$ & $(3.83)$ & $(7.25)$ & $(5.05)$ & $(3.08)$ & 0.240 \\
BMI $\left(\mathrm{kg} / \mathrm{m}^{2}\right)$ & 24.39 & 24.33 & 25.97 & 23.37 & 23.97 & 0.094 \\
& $(2.44)$ & $(2.09)$ & $(3.16)$ & $(2.24)$ & $(1.78)$ & \\
Weight $(\mathrm{kg})$ & 61.62 & 61.40 & 64.36 & 59.57 & 61.25 & 0.435 \\
& $(6,51)$ & $(5.57)$ & $(9.25)$ & $(5.27)$ & $(5.49)$ & \\
Height $(\mathrm{cm})$ & 159.00 & 158.90 & 157.40 & 159.70 & 159.83 & 0.733 \\
& $(5.38)$ & $(5.06)$ & $(8.16)$ & $(3.16)$ & $(4.56)$ & \\
\hline
\end{tabular}

SD = Standard deviation; CG: Control Group (without any training); EG1: Experimental Group 1 (cognitive training); EG2: Experimental Group 2 (cognitive and physical training); EG3: Experimental Group 3 (physical training).

Participants were randomly assigned to the control group (CG; $n=11$ ), which did not perform any training program; Experimental Group $1($ EG1; $n=10)$, which after an initial evaluation did a cognitive training program; Experimental Group 2 (EG2; $n=10)$, which combined a physical and cognitive training program; Experimental Group 3 (EG3; $n=12$ ), which completed a physical training program. Randomization was conducted independently by a research assistant who was not involved in the data collection, using random numbers generated in Microsoft Excel 2010 (Redmond, WA, USA). A recruitment flowchart of the participants is reported in Figure 1.

The inclusion criteria were: (a) women older than 80 years old; (b) prosthesis-free; (c) free of any pathologies associated with an increased risk of falling (e.g., Parkinson's disease); (e) independently ambulatory; (f) free of any disease that requires daily medications that may affect gait performance (to avoid any influence on fitness measures); (g) any pathologies or diseases that imply cardiorespiratory risk with physical effort. The exclusion criteria were: (a) cardiovascular diseases such as ischemic heart diseases or stroke; (b) any other pathology that prevents them to move without help; (c) any cognitive disease that did not allow to understand the protocol of evaluation, or the exercises to complete during training program; (e) not attending to $90 \%$ of training sessions.

We followed the ethical recommendation approved in the Declaration of Helsinki (2013). In addition, we followed the directives of the European Union on Good Clinical Practice (111/3976/88 of July 1990), as specified in a National legal framework for human clinical research (Royal Decree 561/1993 on clinical essays). The study was approved by the Ethics Committee of the University of Jaén (Protocol Code: OCT.20/7.PRY). 


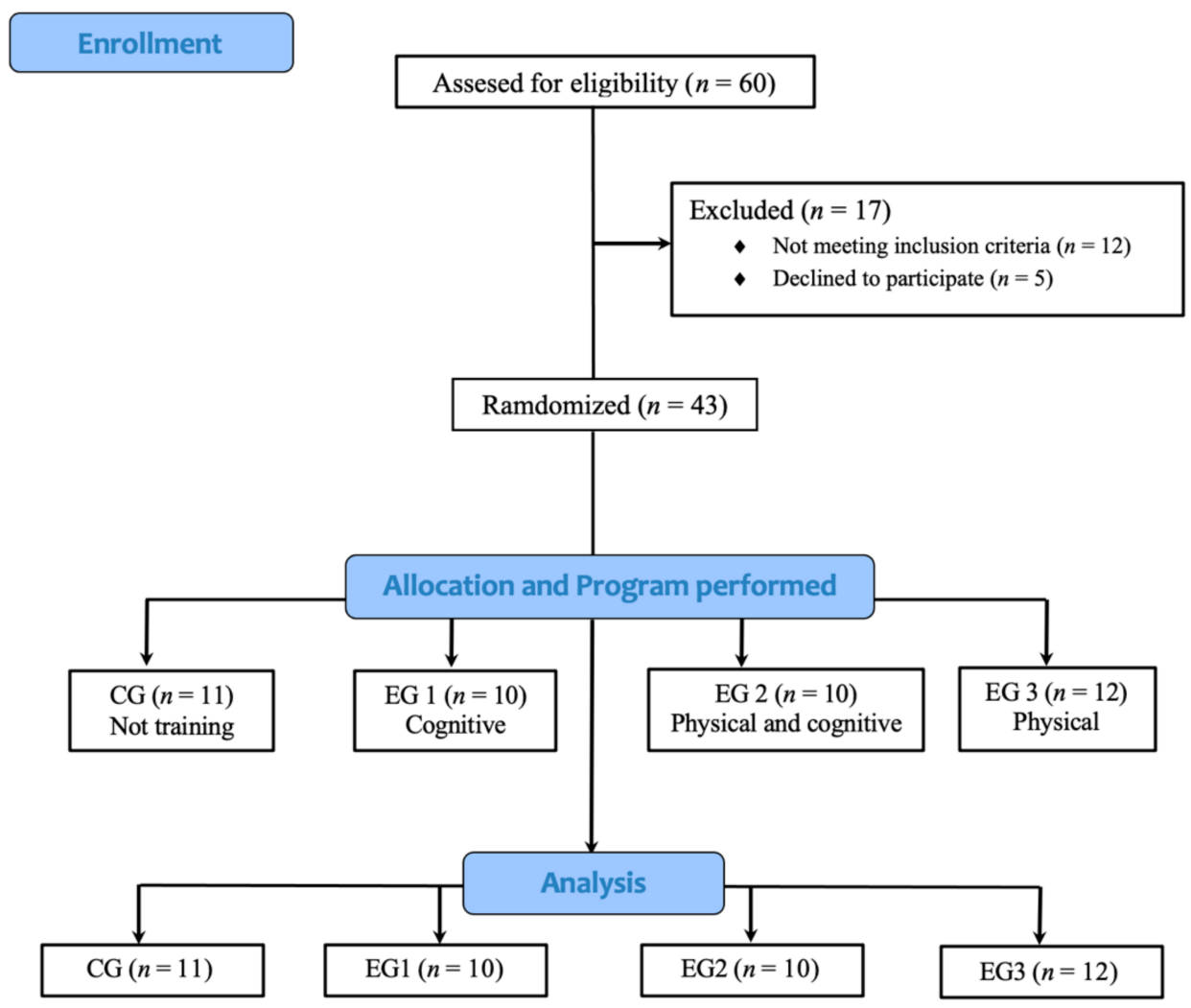

Figure 1. Participant's recruitments flowchart.

\subsection{Materials and Testing}

To assess physical fitness, we used different methods.

(a) 2 Minute Step Test (2MST), consisting of a gait on the site without displacement. The evaluator counted the number of times that the right knee reached the required height in $2 \mathrm{~min}$. Before starting the test, we measured the height to which the participant had to raise the knee. We carried a cord from the iliac crest to the middle of the patella, then held it from the iliac crest and bent it in half, marking a point in the middle of the thigh that indicated the height of the lifted knee. To visualize the height of the step we transferred the mark of the thigh to the wall. We put a piece of tape on the wall so the participant had a visual reference. On the signal "go" the participant began stepping (not running) in place, raising each knee to the mark on the wall, for as many times as possible in the $2 \mathrm{~min}$ period. If the proper knee height could not be maintained, we asked the participant to slow down, or to stop until they could regain the proper form, but kept the stopwatch running. At the end of the test, we provided a cool down by asking the participant to walk slowly for a minute. A chronometer was required for this test [31].

(b) Handgrip strength (HS) was assessed in a bipedal position, with the arm stretched at an angle of $30^{\circ}$ to the trunk, and, without support, exerting force on the dynamometer. We measured HS of the dominant hand three times. A total recovery was allowed between, and we recorded the best one for statistical analysis [32]. We used a Grip Strength Dynamometer TKK.5101 adaptive manual pressure dynamometer, with precision of $0.1 \mathrm{Kg}$, as used in previous studies [33].

(c) For measuring the visual-acoustic reaction time (V-ART) we used OptoGait system (Optogait ${ }^{\circledR}$ Microgate, Bolzano, Italia) to measure V-ART. Optogait is an optical data acquisition system composed of a transmitter and a receiver bar. Each $1 \mathrm{~m}$ bar contains 96 Infrared LEDs ( $1.041 \mathrm{~cm}$ resolution) and is located on the transmitter bar, continuously communicating with the LEDs located on the receiver bar. The bars measure flight and contact times during execution with an accuracy of 1/1000 of a second. Optogait registered the reaction time when the participant's foot stopped touching the ground. It showed high 
concurrent reliability [34]. We assessed both feet; the participant had to stand with one foot resting between the two bars of the platform and the other outside of the bars, facing a screen with speakers. The participant lifted the foot which was between the transmitter bars when a visual or auditory stimulus appeared. Two repetitions (randomized) of the visual stimulus and two of the acoustic stimuli were made per leg, selecting the average for statistical analysis.

To assess cognitive function, we used different tests:

(a) The Stroop Test [35] assessed color-word interference and selective attention. The test consisted of three subtests. In Subtest I, 10 rows $\times 10$ columns of color names (red, blue, green, and yellow) were printed in black on white cardboard. The time needed to read the color names in a loud voice was registered. In Subtest II, the same number of correspondingly colored patches were printed (the colors had to be named). In Subtest III, the color names were printed in incongruously colored ink, e.g., the word green could be printed in red. The color of the ink was be named. We used the Spanish version [36].

(b) The D2 test [37] is a limited-time test to measure selective attention and mental concentration, through the ability to selectively attend to certain relevant aspects of a task while ignoring irrelevant ones (e.g., performing a selective search). It was completed as quickly and accurately as possible. The test consisted of 14 rows (trials), each with 47 interspersed " $\mathrm{p}$ " and " $\mathrm{d}$ " characters. The characters had one to four dashes that were configured individually or in pairs above and/or below each letter. The target symbol was $\mathrm{a}$ " $\mathrm{d}$ " with two dashes (hence " $\mathrm{d} 2$ "), regardless of whether the dashes appeared both above the " $d$ ", both below the " $d$ ", or one above and one below the " $d$ ". Thus, a " $p$ " with one or two dashes and a " $\mathrm{d}$ " with more or less than two dashes were distracters. The participant's task was to cancel out as many target symbols as possible, moving from left to right, with a time limit of $20 \mathrm{~s} / \mathrm{trial}$.

(c) The Trail Making Test (TMT) [38] consisted of two parts (TMT-A and TMT-B). The TMT-A consisted of a standardized page on which the numbers 1 to 25 were scattered within circles, and the participants were asked to connect the numbers in order as quickly as possible. Similarly, the TMT-B consisted of a standardized page that included the numbers 1 to 13 and the letters $A$ to $L$, which were randomly distributed. The participants were instructed to draw lines connecting numbers and letters (ascending and alphabetical) order, alternating numbers and letters. Before starting the test, a practice trial of six items was administered to the participants to make sure that they understood both tasks. When a participant made an error during the test performance, the examiner pointed it out and explained it, then guided the participant to the last circle completed correctly. Then, the evaluator encouraged the participant to continue with the task. A maximum time of $300 \mathrm{~s}$ was allowed before discontinuing the test. Direct scores of TMT were the time in seconds taken to complete each task (A and B).

\subsection{Procedures}

The training program was conducted over 8 weeks and included five weekly sessions from Monday to Friday (60 min each) with a total of 40 sessions. We conducted the training over 2 weeks to familiarize the participants with the exercises and tasks that they should complete during the intervention. The sessions were applied by a specialist (physical coach or/and psychologist, in each case). The protocol for the session began with a standard warm-up (10 min), followed by the main part of the session (40 min) and then a cool down was done (10 min) for EG2 and EG3. In addition, the difficulty of the task was increased each week, with the intervention program divided in two different levels: level 1 from week 1 to 4 ; and level 2 from week 5 to 8 (Figure 2). 


\begin{tabular}{|c|c|c|}
\hline \multicolumn{3}{|c|}{ Cognitive training } \\
\hline & $\begin{array}{c}\text { Level 1 } \\
\end{array}$ & Level 2 \\
\hline Monday & $\begin{array}{l}\text { - Write objects that you can find in different places. E.g., house, car... } \\
\text { - Write the opposite word (e.g., good, rich...) } \\
\text { - Mark a specific number in the follow sequence. E.g., } 98654321058635498206 \ldots \\
\text { - Write the name of the person who works in... E.g., bank, bar, school... }\end{array}$ & $\begin{array}{l}\text { - Write objects animals that you can find in a specific place. E.g., stationery, desk... } \\
\text { - Write animals which do not have four legs } \\
\text { - Choose the number } 3 \text { among the follow sequence. E.g., } 545365893623569135985332 \\
\text { - Mark the vocals in the follow sequence. E.g., NCEDSATHYKLOMCZASDFCUTGEF... }\end{array}$ \\
\hline Tuesday & $\begin{array}{l}\text { - Follow the number sequence to reach number } 20 \text {. E.g., } 2,4,6, \ldots \\
\text { - You should solve mentally the following arithmetic operations. E.g., } 5+4,10-4,2 \times 2, \ldots \\
\text { - Mark with a circle the number with only two digits. }\end{array}$ & $\begin{array}{l}\text { - Order the follow numbers from lower to highest. E.g., } 52 / 31 / 42 / 63,25 / 36 / 52 / 69 \ldots \\
\text { - You should solve mentally the following arithmetic operations. E.g., } 25+12,15-10,12 \times 10 \ldots \\
\text { - You should mark in the sequence the even numbers in red and odd numbers in blue }\end{array}$ \\
\hline Wednesday & $\begin{array}{l}\text { - Imagine that you are spending a rest day in the beach, what do you should take? } \\
\text { - Can you tell me what is the difference among these words? E.g., wine and beer, football } \\
\text { and basketball... } \\
\text { - You should order the follows actions to have a logical sequence. E. g., To go to a } \\
\text { museum... a) buy the ticket, b) exit the museum, c) visit the museum, d) enter the museum }\end{array}$ & $\begin{array}{l}\text { - In the following words, you should mark which one has less relation with the others. E.g., Bicycle, } \\
\text { boat, train, plane... } \\
\text { - Tell the name of an object which is: a) blue, b) small and plastic, c) square and made of cardboard... } \\
\text { - We are going to a wedding, mark the word which has no relation with this event. E.g., Cake, rice, car, } \\
\text { flashlight }\end{array}$ \\
\hline Thursday & $\begin{array}{l}\text { - Tell me } 4 \text { short popular histories which are common in Spain } \\
\text { - Repeat the follows list of words. E.g., a) Fantastic, summer, pencil, shoe, fight, chocolate } \\
\text { b) Elephant, caramel, window, pencil, magazine }\end{array}$ & $\begin{array}{l}\text { - Tell me what we celebrate in Spain in these days. a) } 1^{\text {st }} \text { of January, b) } 6^{\text {th }} \text { of January, c) } 1^{\text {st }} \text { of May... } \\
\text { - Complete the follow sentences...a) The capital of Spain is...b) Winter begin in... } \\
\text { - Explain what do you remember of these days. A) Weeding's day, b) military service... }\end{array}$ \\
\hline Friday & $\begin{array}{l}\text { - Draw the upper figure in the lower point set } \\
\text { - Observe the following picture, ihow many animals appear in it? } \\
\text { - Write the name or the meaning of the following symbols... }\end{array}$ & $\begin{array}{l}\text { - Among the different figures, you should mark which one has the sames size } \\
\text { - You should reproduce this action with mimics. A) wash your face, b) drive a car... } \\
\text { - Read the follow text and try to respond to this question... }\end{array}$ \\
\hline \multicolumn{3}{|c|}{$\begin{array}{ll}\text { - Write the name or the meaning of the following symbols... } & \text { Physical and cognitive training }\end{array}$} \\
\hline Monday & $\begin{array}{l}\text { - Repeat the following track. E.g., Open the windows, open the door, close the door... } \\
\text { - Pass balls among partners clockwise and/or counterclockwise } \\
\text { - Repeat the sequence. E.g., the monitor performed } 4 \text { movements and they have to repeat }\end{array}$ & $\begin{array}{l}\text { - Draw in the air the picture that the monitor has drawn previously and continue the sequence } 2,4,6 \ldots \\
\text { - Throwing or kicking a ball towards each other counting throws and telling partner names, hair colour. } \\
\text { - Continue the history with gesture and words }\end{array}$ \\
\hline Tuesday & $\begin{array}{l}\text { - Orientation exercises through a room with map help. Follow the instruction and describe } \\
\text { something that you can find in a market, room, house... }\end{array}$ & $\begin{array}{l}\text { - Orientation exercises through a room without map help following the instruction to the monitor. You } \\
\text { should count forward and backward follow the sequence numbers or things. E.g., } 1,3,5 \text { or } 10,8,6,4 \ldots\end{array}$ \\
\hline Wednesday & $\begin{array}{l}\text { - Perform the following job with mimic. E.g., carpenter, electrician, bricklayer, waiter } \\
\text { - Following the arm sequence and at the same time you have to count forward } \\
\text { - Repeat the movements sequence while you are explaining how is your day }\end{array}$ & $\begin{array}{l}\text { - Following the arm sequence with an extra weight }(1-2 \mathrm{~kg}) \text { and counting forward/backward } \\
\text { - Balance of one leg (right and left) and raise the arm contrary to the leg whereas you have to continue } \\
\text { the number sequence. E.g., } 1,3,5,7 \text { or } 30,27,24,21 \ldots\end{array}$ \\
\hline Thursday & $\begin{array}{l}\text { - Follow the instructions with the pencils on the table: a) at ake one, three, six... b) make } \\
\text { groups of } 6 \ldots \text { whereas you are telling the names of your friends, animals... } \\
\text { - Complete the track while you have to count forward/backward }\end{array}$ & $\begin{array}{l}\text { - Follow the instructions with the pencils on the table: a) make groups of } 6,12 . \text { b) make } 2 \text { groups of } 6 \\
\text { pencils... whereas you respond the questions. E.g., Capital of Spain..., counting backward... } \\
\text { - Complete the track and count backward starting in the highest number that you remember. E.g., } 40-41\end{array}$ \\
\hline Friday & $\begin{array}{l}\text { - Throwing balls in the air and catching with the same hand whereas repeat the alphabet } \\
\text { - Throwing balls to your partner and catching it with the opposite hand whereas follow the } \\
\text { sequence number. E.g., } 1,3,5 \text { or } 2,4,6 \ldots\end{array}$ & $\begin{array}{l}\text { - Bounce and spelling different actions randomly (e.g., things that we to buy in a supermarket...) } \\
\text { - kick or throw the ball to a partner and receive with one feet or hand while you have to follow the } \\
\text { sequence of numbers counting backwards. E.g., } 30,27,24,21 \ldots \text { or } 31,28,25 \ldots\end{array}$ \\
\hline \multicolumn{3}{|c|}{$\begin{array}{l}\text { Sequence number. E.g., } 1,3,5 \text { or } 2,4,0 \ldots \\
\text { Physical training }\end{array}$} \\
\hline Monday & $\begin{array}{l}\text { - Raise the knee and balance } 2 \text { seconds, } 1 \times 10 \text { rep each } \\
\text { - Sit and up (10 rep) } \\
\text { - Rowing with a light stick ( } 12 \mathrm{rep})\end{array}$ & $\begin{array}{l}\text { - Raise the knee and balance } 2 \text { seconds, } 2 \times 10 \text { rep each. } \\
\text { - Sit and up ( } 2 \times 12 \text { rep). } \\
\text { - Rowing with a light stick ( } 12 \text { rep) }\end{array}$ \\
\hline Tuesday & $\begin{array}{l}\text { - Upper body rotation (12 rep) } \\
\text { - Strength exercise with elastic band (12 rep) } \\
\text { - Bicep curls (1x10 rep) }\end{array}$ & $\begin{array}{l}\text { - Upper body rotation }(2 \times 12 \text { rep) } \\
\text { - Strength exercise with elastic band }(2 \times 12 \text { rep }) \\
\text { - Bicep curls }(2 \times 10 \text { rep })\end{array}$ \\
\hline Wednesday & $\begin{array}{l}\text { - Walking in preferred speed }(15 \mathrm{~min}) \\
\text { - Walking following the lines }(5 \mathrm{~min}) \\
\text { - Walking in different directions (forward, backwards, lateral...) }(5 \mathrm{~min})\end{array}$ & + Carrying a backpack (1-2 kg) \\
\hline Thursday & $\begin{array}{l}\text { - Strength exercise with elastic band (12 rep) } \\
\text { - Bicep curls }(1 \mathrm{x} 10 \text { rep } \mathrm{x} 1 \mathrm{~kg}) \\
\text { - Triceps extension }(1 \times 10 \times 1 \mathrm{~kg} \text { rep })\end{array}$ & $\begin{array}{l}\text { - Strength exercise with elastic band ( } 2 \times 12 \text { rep }) \\
- \text { Bicep curls }(2 \times 10 \text { rep } \times 2 \mathrm{~kg}) \\
\text { - Triceps extension }(2 \times 10 \mathrm{rep} \times 2 \mathrm{~kg})\end{array}$ \\
\hline Friday & $\begin{array}{l}\text { - Walking as quickly as possible speed }(10 \mathrm{~min}) \\
\text { - Walking as quickly as possible following the lines }(5 \mathrm{~min}) \\
\text { - Walking in different directions (forward, backwards, lateral...) }(5 \mathrm{~min})\end{array}$ & $\begin{array}{l}\text { - Walking } 10 \text { minutes changing the directions } \\
\text { - Slalom around a circuit }(4 \text { pikes) } \\
\text { - Walking and avoid the little obstacles }\end{array}$ \\
\hline
\end{tabular}

Figure 2. Example of the task performed by each experimental group.

Sessions for EG1 were implemented with individual tasks. Session one was devoted to language and selective attention; session two, calculation operation; session three, to executive function; session four, to memory; and session five, to praxis and gnosis. The sequence was repeated every week. EG2 combined physical and cognitive training sessions that consisted of motor games and motor tasks with cognitive involvement (based on DT paradigm). Session modules were designed to allow the adaptation of the content to the level of the participants and to increase the difficulty each week. Intensity was adjusted to the ability to perform functional movements in which self-loading was used as resistance. We emphasized the aerobic capacity, strength, and motor aptitude. EG3 did physical training through individual tasks, based on previous studies [9]. These sessions consisted of directed physical exercises without cognitive implication, focusing on aerobic capacity, strength, and motor aptitude. Functional movements with body weight and displacements were used, adjusting the intensity every week (Figure 3).

\subsection{Data Analysis}

Statistical Analyses Data were analyzed using SPSS, v.22.0 for Windows (SPSS Inc., Chicago, IL, USA). The significance level was set at $p<0.05$. Descriptive data are reported in terms of means, standard deviations (SD), and median ( $95 \% \mathrm{CI})$. Tests of normal distribution and homogeneity (Kolmogorov-Smirnov and Levene's, respectively) were conducted on all data before analysis. The results of the normality and homogeneity tests revealed that some data required nonparametric tests for analysis. Consequently, we conducted Kruskal-Wallis test and Mann-Whitney $U$ test. Finally, a Sperman correlation analysis between physical, and cognitive variables was done. 


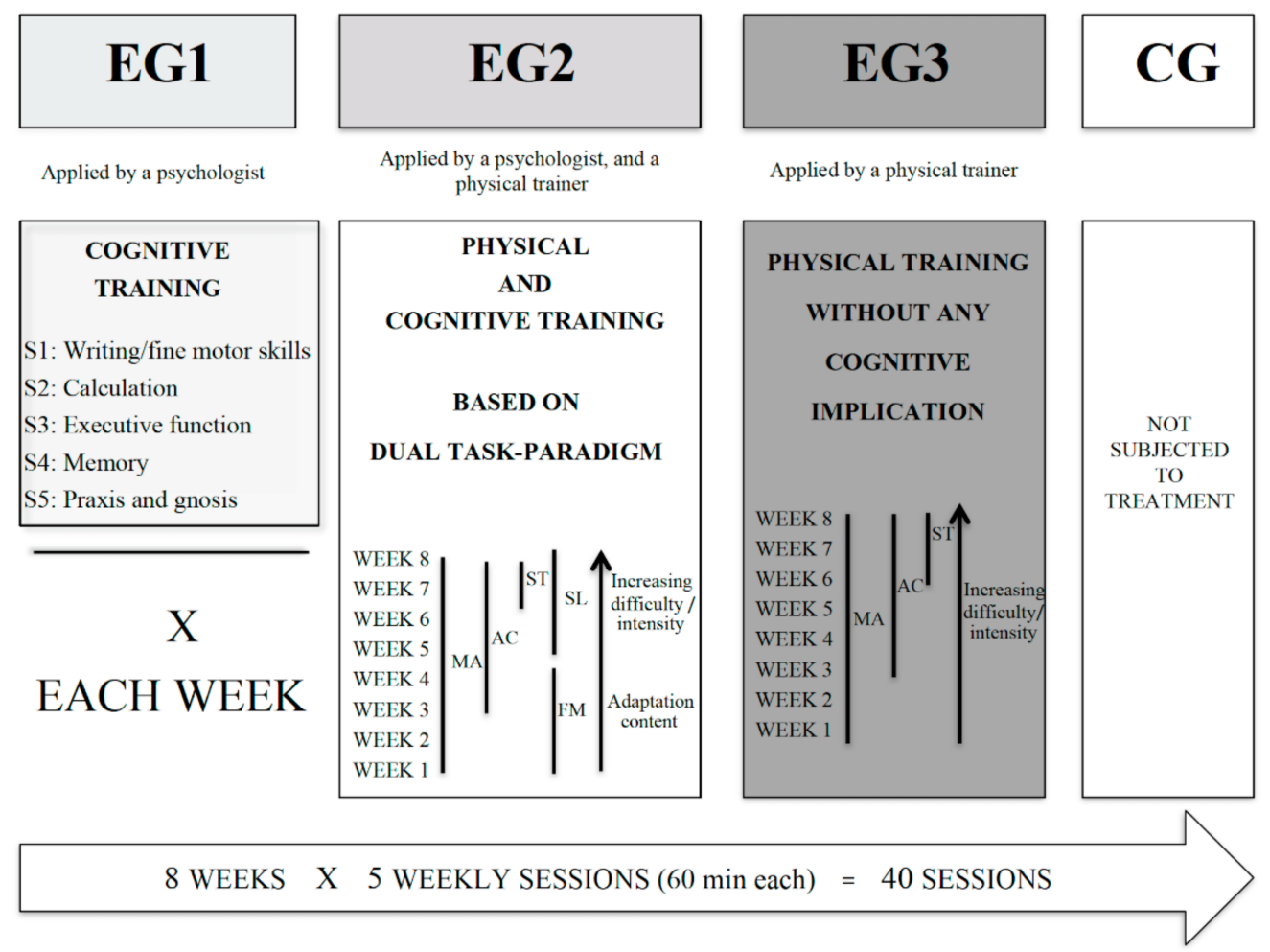

Figure 3. Study design. EG: experimental group; CG: control group; MA: motor aptitude; AC: aerobic capacity; S1; S2; S3; S4, and S5: sessions conducted from Monday (S1) to Friday (S5); ST: strength training; FM: functional movement; SL: self-loading.

\section{Results}

Table 1 shows the age, and anthropometrics characteristics of the participants. No significant differences were observed in any variable.

Table 2 provides cognitive variables analyzed in the pre-and post-tests and the differences between assessments. It shows that there are significant differences among the three experimental groups, showing an improvement in each cognitive variable that we evaluated.

The results show that there are significant differences between CG and CG1, CG2, and CG3 $(p<0.05)$. It is important to emphasize that CG did not have any improvement showing a decrement in the performance in all tasks that we assessed. On the contrary, the experimental groups obtained an improvement in the performance of the cognitive variables.

Table 3 compares the results of the physical tests during the pre- and post-tests, also the increments between assessment. We found significant differences between CG and EG1, EG2, and EG3 in all variables analised. Regarding 2MST, there was significant differences between CG1 and CG3 $(p<0.05)$. In addition, we found significant differences throughout EG2 and EG3 in V-ART variable. 
Table 2. Cognitive variables in pre- and post-test.

\begin{tabular}{|c|c|c|c|c|c|}
\hline Variables & Groups & $n$ & $\begin{array}{l}\text { Pre-Test Median } \\
\quad(95 \% \mathrm{CI})\end{array}$ & $\begin{array}{c}\text { Post-Test } \\
\text { Median }(95 \% \text { CI })\end{array}$ & $\begin{array}{c}\text { Increase } \\
\text { Median }(95 \% \mathrm{CI})\end{array}$ \\
\hline & CG & 11 & $13.17(9.78 / 27.34)$ & $7.57(3.05 / 14.81)$ & $-5.82(-8.25 /-4.19) \mathrm{a}$ \\
\hline Stroop & EG1 & 10 & $13.95(9.65 / 24.87)$ & $11.96(8.70 / 19.63)$ & $-3.23(-4.47 /-1.00) b$ \\
\hline (total points) & EG2 & 10 & $12.90(1.02 / 23.91)$ & $9.55(5.54 / 21.02)$ & $0.14(2.22 / 2.78) \mathrm{b}$ \\
\hline \multirow{3}{*}{$p$-value (group time) } & EG3 & 12 & $17.32(8.83 / 36.16)$ & $14.71(5.34 / 35.20)$ & $-2.16(-2.80 /-0.90) b$ \\
\hline & & & 0.709 & 0.426 & 0.002 \\
\hline & CG & 11 & $145.00(59.00 / 252.00)$ & $84.00(69.00 / 136.00)$ & $-17.00(-94.00 / 2.00) \mathrm{a}$ \\
\hline D2 & EG1 & 10 & $82.50(37.01 / 128.00)$ & $134.00(68.00 / 166.50)$ & $20.00(5.00 / 76.50) \mathrm{b}$ \\
\hline \multirow[t]{2}{*}{ (total points) } & EG2 & 10 & $147.50(96.00 / 229.00)$ & $186.50(137.00 / 247.00)$ & $22.00(9.00 / 42.00) b$ \\
\hline & EG3 & 12 & $94.00(50.00 / 236.00)$ & $130.00(48.234 / 122.33)$ & $7.50(-2.00 / 25.85) b$ \\
\hline \multirow[t]{2}{*}{$p$-value (group time) } & & & 0.325 & 0.091 & 0.001 \\
\hline & CG & 11 & $42.00(5.00 / 79.00)$ & $10.00(7.00 / 15.00)$ & $-30.00(-68.00 / 5.00) \mathrm{a}$ \\
\hline D2 & EG1 & 10 & $3.00(-2.41 / 15.50)$ & $20.50(3.00 / 35.98)$ & $16.00(4.00 / 34.00) \mathrm{b}$ \\
\hline \multirow[t]{2}{*}{ (concentration) } & EG2 & 10 & $32.00(23.00 / 94.00)$ & $66.00(22.50 / 140.50)$ & $10.00(3.50 / 35.00) b$ \\
\hline & EG3 & 12 & $21.00(6.00 / 99.00)$ & $22.50(10.50 / 108.00)$ & $4.50(3.00 / 7.00) \mathrm{b}$ \\
\hline \multirow[t]{2}{*}{$p$-value (group time) } & & & 0.021 & 0.096 & 0.002 \\
\hline & CG & 11 & $229.00(122.00 / 349.00)$ & $254.00(72.89 / 143.39)$ & $19.00(-14.00 / 45.00) \mathrm{a}$ \\
\hline TMT & EG1 & 10 & $303.50(252.00 / 347.47)$ & $211.00(179.50 / 252.00)$ & $-76.50(-95.00 /-52.00) b$ \\
\hline \multirow[t]{2}{*}{$(\operatorname{task} A)(\mathrm{s})$} & EG2 & 10 & $222.50(146.50 / 291.00)$ & $138.00(83.00 / 206.00)$ & $-66.50(-81.00 /-50.00) b$ \\
\hline & EG3 & 12 & $205.80(115.50 / 261.60)$ & $133.20(34.80 / 180.31)$ & $-57.90(-68.40 /-48.60) b$ \\
\hline \multirow[t]{2}{*}{$p$-value (group time) } & & & 0.092 & 0.021 & $<0.001$ \\
\hline & CG & 11 & $362.00(316.00 / 454.00)$ & $430.00(361.00 / 470.00) \mathrm{a}$ & $41.00(29.00 / 51.00) \mathrm{a}$ \\
\hline TMT & EG1 & 10 & $415.50(298.00 / 468.97)$ & $294.50(275.05 / 372.00) \mathrm{b}$ & $-77.00(-116.00 /-28.00) b$ \\
\hline \multirow[t]{2}{*}{ (task B) (s) } & EG2 & 10 & $305.00(246.00 / 409.50)$ & $275.50(230.00 / 312.50) b$ & $-59.50(-90.00 /-14.00) b$ \\
\hline & EG3 & 12 & $324.29(274.20 / 450.00)$ & $264.00(227.10 / 421.20) b$ & $-59.39(-69.59 /-32.99) b$ \\
\hline$p$-value (group time) & & & 0.352 & 0.001 & $<0.001$ \\
\hline
\end{tabular}

CG: Control Group (without any training); EG1: Experimental Group 1 (cognitive training); EG2: Experimental Group 2 (cognitive and physical training); EG3: Experimental Group 3 (physical training); Stroop = Stroop Test; D2 = D2 Test; TMT: Trail Making Test; Letter in the lower case indicate a significant difference among groups; (i.e., a, b).

Table 3. Physical variables in pre- and post-test.

\begin{tabular}{|c|c|c|c|c|c|}
\hline Variables & Groups & $n$ & $\begin{array}{c}\text { Pre-Test } \\
\text { Median (95\% CI) }\end{array}$ & $\begin{array}{c}\text { Post-Test } \\
\text { Median (95\% CI) }\end{array}$ & $\begin{array}{c}\text { Increase } \\
\text { Median (95\% CI) }\end{array}$ \\
\hline & CG & 11 & $17.70(14.40 / 19.20)$ & $17.00(12.60 / 18.50)$ & $-0.69(-1.80 / 0.00) \mathrm{a}$ \\
\hline HS & EG1 & 10 & $12.85(9.80 / 16-50)$ & $13.25(10.85 / 18.50)$ & 1.35 (0.30/1.69) b \\
\hline$(\mathrm{Kg})$ & EG2 & 10 & $15.95(10.10 / 19.15)$ & $17.45(11.80 / 21.00)$ & $1.65(1.30 / 2.00) b$ \\
\hline & EG3 & 12 & $15.05(10.10 / 18.30)$ & $15.95(11.40 / 19.20)$ & $1.35(0.59 / 1.75) b$ \\
\hline$p$-value (group time) & & & 0.108 & 0.551 & $<0.001$ \\
\hline & CG & 11 & $84.00(77.00 / 86.00)$ & $81.00(77.00 / 86.00)$ & $0.00(-4.00 / 0.00) \mathrm{a}$ \\
\hline 2MST & EG1 & 10 & $71.50(57.00 / 82.48)$ & $78.00(63.00 / 88.00)$ & $5.50(2.00 / 7.00) \mathrm{b}$ \\
\hline (step number) & EG2 & 10 & $83.00(79.00 / 90.00)$ & $94.50(87.00 / 97.00)$ & $11.00(4.00 / 14.00) b, c$ \\
\hline & EG3 & 12 & $82.50(56.00 / 97.00)$ & $85.50(67.00 / 104.00)$ & $9.00(7.00 / 12.50) \mathrm{c}$ \\
\hline$p$-value (group time) & & & 0.171 & 0.015 & $<0.001$ \\
\hline & CG & 11 & $0.79(0.67 / 1.03) \mathrm{a}$ & $1.03(0.82 / 1.31)$ & $0.23(0.11 / 0.34) \mathrm{a}$ \\
\hline V-ART & EG1 & 10 & $1.26(1.05 / 1.34) b$ & $0.92(0.85 / 1.05)$ & $-0.32(-0.37 /-0.12) b, c$ \\
\hline (s) & EG2 & 10 & $1.18(0.90 / 1.45) b, c$ & $0.89(0.77 / 1.41)$ & $-0.33(-0.42 /-0.03) b$ \\
\hline & EG3 & 12 & $0.89(0.85 / 1.07)$ a,c & $0.81(0.63 / 0.92)$ & $-0.20(-0.21 /-0.09) \mathrm{c}$ \\
\hline$p$-value (group time) & & & 0.001 & 0.067 & $<0.001$ \\
\hline
\end{tabular}

CG: Control Group (without any training); EG1: Experimental Group 1 (cognitive training); EG2: Experimental Group 2 (cognitive and physical training); EG3: Experimental Group 3 (physical training); HS: handgrip strength; 2MST: 2 Minute Step Test; V-ART: Visual-Acoustic reaction time (second); Letter in the lower case indicate significant difference among groups (i.e., a, b, c).

Table 4 reflects the Spearman correlation analysis between physical and cognitive function variables in relation to the increase in measures after the intervention (pre-test and post-test). It should be noted that there is a strong correlation among physical and cognitive variables. 
Table 4. Correlation analysis between physical and cognitive variables with measure increment after intervention.

\begin{tabular}{|c|c|c|c|c|c|c|c|c|}
\hline & $\Delta$ Stroop & $\begin{array}{c}\Delta \mathrm{D} 2 \\
\text { (Total Points) }\end{array}$ & $\begin{array}{c}\Delta \mathrm{D} 2 \\
\text { (Concentration) }\end{array}$ & $\begin{array}{l}\Delta \text { TMT } \\
\text { Task-A }\end{array}$ & $\begin{array}{l}\Delta \text { TMT } \\
\text { Task-B }\end{array}$ & $\Delta 2 \mathrm{MST}$ & $\Delta \mathrm{V}$-ART & $\Delta \mathrm{HS}$ \\
\hline$\Delta$ Stroop & 1 & 0.104 & 0.172 & $-0.352 *$ & -0.224 & $0.336^{*}$ & -0.311 * & 0.219 \\
\hline D2 (total points) & & 1 & 0.380 & $-0.397^{* *}$ & $-0.530^{* *}$ & $0.511^{* *}$ & $-0.470^{* *}$ & $0.545^{* *}$ \\
\hline$\Delta \mathrm{D} 2$ (concentration) & & & 1 & -0.347 * & $-0.307^{*}$ & $0.348 *$ & -0.209 & $0.409 * *$ \\
\hline$\Delta$ TMT Task-A & & & & 1 & $0.495^{* *}$ & -0.350 * & $0.417^{* *}$ & $-0.513^{* *}$ \\
\hline$\Delta$ TMT Task-B & & & & & 1 & $-0.458^{* *}$ & $0.577^{* *}$ & -0.546 ** \\
\hline$\Delta 2 \mathrm{MST}$ & & & & & & 1 & $-0.366^{*}$ & $0.560 * *$ \\
\hline$\Delta \mathrm{V}$-ART & & & & & & & 1 & $-0.484^{* *}$ \\
\hline$\Delta \mathrm{HS}$ & & & & & & & & 1 \\
\hline
\end{tabular}

TMT: Trail Making Test; 2MST: Minute Step Test; V-ART: Visual-Acoustic reaction time; HS: handgrip strength; ${ }^{*} p<0.05,{ }^{* *} p<0.01$.

\section{Discussion}

The aim of this study was to determine the effects of physical and cognitive training programs, as well as their combination, on the cognitive functions and physical fitness in women over 80 years old. Our initial hypothesis was that a combined program of physical and cognitive exercise based on a DT paradigm would have a greater effect on improved physical and cognitive abilities in older adults compared to when cognitive or physical training is performed independently.

The main finding in our study reveals that the participants responded positively to an intervention based on either cognitive or physical training or their combination in relation to the improvement of functionality in elderly people. Nonetheless, it has not been possible to corroborate our initial hypothesis since we did not find significant differences among intervention groups.

In our study, the participants who join in an experimental group (i.e., EG1, EG2, and EG3) showed a physical and cognitive improvement, independently to the training program performed. In this regard, we have not found significant different among intervention groups. We only found significant differences in some physical variables (i.e., 2MST, and V-art), the EG3 achieved greater performance. Hence, we cannot confirm which training program induces a greater improvement to the participants. Considering the results obtained by the CG, after only two months negative effects on cognitive and physical variables resulting from the aging process were analyzed. Consequently, physical-cognitive training programs applied individually or together, including DT programs, help to prevent the deterioration associated with aging. In this regard, a previous study noted that exercise can improve cognitive function and physical capacities in this population which has been related with a better quality of life [15].

\subsection{Cognitive Variables}

Regarding cognitive variables, our results showed an improvement in EG1, EG2, and in all variables that when the training program was performed in physical or cognitive capacities, or in both of them. The results of the current study agree with those found by Valencia et al. [39], which concluded that 20 sessions of combined cognitive-motor training improves selective attention and conflict resolution and interference. Moreover, Fabre et al. [40] obtained a higher incidence on cognitive function with aerobic-cognitive training than when they were conducted separately. Likewise, Vaughan et al. [18] conducted research that included a single weekly session of $60 \mathrm{~min}$ of multicomponent training. They obtained improvements in the Stroop Test and the Trail Making Test.

Although, recent studies $[10,40]$ indicated that an intervention program which included only aerobic dance exercises in women had improvements on cognitive function, being these results similar to those obtained with a cognitive training exclusively $[16,40]$.

Therefore, aerobic training has effects on attention and execution processes in older people, both in a combined physical-cognitive program and in an exclusively physical way [15]. 


\subsection{Fitness Variables}

The Spearman correlation analysis reveals a significant association between physical capacity and cognitive functions, specifically, in concentration and executive function. Our findings confirm the association between physical capacities and cognitive capacities. It is corroborated in a previous research [3]. Consequently, physical activity through aerobic or resistance training program is a strategy to protect physical and cognitive function $[10,11]$.

Regarding HS, the three training programs resulted in significant improvements, whereas the CG showed a decrease on it. Considering that previous studies have concluded that there is a relationship between strength levels and quality of life [1], it is necessary to keep in mind that in the elderly, physical inactivity induces a progressive loss of strength in the upper body in a short time as in the CG in our intervention. Morevover, in accordance with other authors, we found a relationship between HS and cognitive abilities [34] as a factor of cognitive protection in vulnerable ages [23], which could have an impact on better performance in health [41].

In addition, V-ART improved significantly in the three experimental groups. Specifically, the EG1, and EG2 obtained a greater improvement with respect to EG3. However, the CG got an increment in the reaction time regarding the experimental groups. Our results are contrary to the findings of previous research, in which the reaction time after physical training did not improve [29]. This could be justified by the characteristics of the implemented tasks. Our participants performed training based on DT paradigm which included decision tasks and motor-game activities whereas they have to focus their attention on another activity. It seems to be an appropriate stimulus to respond more quickly cognitively and in a motor way [42]. Herzog et al. [27] found an association among different situations that require executive coordination, such as complex video games, the commutation of tasks, and divided attention. In the current study, a test that combines visual and auditory stimuli was implemented. Both stimuli appeared randomly, which implied a complex reaction response similar to the actions that participants have to carry out in their daily life activities. In addition, the instrument used allowed discrimination between the reaction time and the movement time. Therefore, the improvement of V-ART with physical-cognitive training that simulates activities of daily living can predict a better maintenance of cognitive abilities and reduce the risk of Alzheimer's at the end of life [27].

According to the 2MST, our result showed an improvement among the three intervention groups showing significant differences between CG1 and EG3. EG3 got a greater improvement. Nonetheless, this improvement does not appear in the CG since this group showed a decrease in relation to their pre-test data. These results are in concordance with previous studies which support the influence of aerobic capacity on the cognitive processes $[16,17,27]$.

A limitation of this study is that the results have not been tested in relation to males. In addition, the sparce number of participants per group could be another limitation, although, the average age of the participants was over 80 years, and it was difficult to find participants to include in our study with the inclusion criteria that we mentioned above. Furthermore, the three physical tests that we conducted could be not enough to avoid a bias of sample. Future investigations must resolve these limitations. Despite these limitations, a strength of the study was the duration of our intervention since was not easy to find participants at this age who want to join in this kind of training programs.

\subsection{Practical Application}

Incorporation of training programs, physical and cognitive, is an important stimulus to improve physical capacities and cognitive functions. Specially, if the training program is based on a DT paradigm since it simulates activities of daily living [43]. Therefore, physical programs should be complemented with cognitive tasks based on motor games, individually and interacting with peers, the resolution of motor problems, and decisionmaking tasks based on the uncertainty of the response. 


\section{Conclusions}

To conclude, performing in a physical or cognitive training, or a combination of both, over 8 weeks improves the physical capacities and cognitive functions in older people and can preserve them from the negative effects of the aging process. Consequently, lack of training at these ages (physical and/or cognitive training) can accelerate the aging process since the deterioration of functional capacities is faster when no training program is performed.

Author Contributions: Conceptualization, J.A.P.-M., J.C.C.-L., and P.Á.L.-R.; methodology, J.A.P.-M., M.D.E.A., and A.A.-A.; software, E.L.-A.; validation, A.A.-A., J.A.P.-M., and P.Á.L.-R.; formal analysis, P.Á.L.-R. and E.L.-A.; investigation, J.A.P.-M., J.C.C.-L., A.A.-A., and M.D.E.A.; data curation, P.Á.L.-R. and E.L.-A.; writing-original draft preparation, J.C.C.-L., J.A.P.-M., and V.S.H.; writing-review and editing, J.C.C.-L., J.A.P.-M., P.Á.L.-R., and V.S.H. All authors have read and agreed to the published version of the manuscript.

Funding: Proyecto Andared. Code number: 0551_PSL_6_E. Financed by the CSIC foundation.

Institutional Review Board Statement: The study was conducted according to the guidelines of the Declaration of Helsinki and approved by the Ethics Committee of University of Jaén (Spain). (Protocol Code: OCT.20/7.PRY).

Informed Consent Statement: Informed consent was obtained from all subjects involved in the study.

Data Availability Statement: Not applicable.

Acknowledgments: Authors want to express their gratitude to the participants who selflessly joined in the study.

Conflicts of Interest: The authors declare no conflict of interest.

$\begin{array}{ll}\text { Abbreviations } \\ \text { BMI } & \text { Body Mass Index } \\ \text { HS } & \text { Handgrip Strength } \\ \text { CG } & \text { Control Group } \\ \text { EG1 } & \text { Experimental Group 1 } \\ \text { EG2 } & \text { Experimental Group 2 } \\ \text { EG3 } & \text { Experimental Group 3 } \\ \text { V-ART } & \text { Visual Art Reaction Time } \\ \text { TMT } & \text { Trail Making Test } \\ \text { 2MST } & \text { 2 Minutes Step Test }\end{array}$

\section{References}

1. Sternäng, O.; Reynolds, C.A.; Finkel, D.; Ernsth-Bravell, M.; Pedersen, N.L.; Dahl Aslan, A.K. Grip strength and cognitive abilities: Associations in old age. J. Gerontol. Ser. B Psychol. Sci. Soc. Sci. 2016, 71, 841-848. [CrossRef] [PubMed]

2. Rönnlund, M.; Nyberg, L.; Bäckman, L.; Nilsson, L.G. Stability, growth, and decline in adult life span development of declarative memory: Cross-sectional and longitudinal data from a population-based study. Psychol. Aging 2005, 20, 3-18. [CrossRef] [PubMed]

3. Auyeung, T.W.; Lee, J.S.W.; Kwok, T.; Woo, J. Physical frailty predicts future cognitive decline - A four-year prospective study in 2737 cognitively normal older adults. J. Nutr. Heal. Aging 2011, 15, 690-694. [CrossRef] [PubMed]

4. López, M.D.; Zamarrón, M.D.; Fernández-Ballesteros, R. Asociación entre la realización de ejercicio e indicadores de funcionamiento físico y cognitivo. Comparativa de resultados en función de la edad. Rev. Esp. Geriatr. Gerontol. 2011, 46, 15-20. [CrossRef]

5. Rezola-Pardo, C.; Arrieta, H.; Gil, S.M.; Yanguas, J.J.; Iturburu, M.; Irazusta, J.; Sanz, B.; Rodriguez-Larrad, A. A randomized controlled trial protocol to test the efficacy of a dual-task multicomponent exercise program in the attenuation of frailty in long-term nursing home residents: Aging-ONDUAL-TASK study. BMC Geriatr. 2019, 19, 6. [CrossRef]

6. Woollacott, M.; Shumway-Cook, A. Attention and the control of posture and gait: A review of an emerging area of research. Gait Posture 2002, 16, 1-14. [CrossRef]

7. Montero-Odasso, M.; Bergman, H.; Phillips, N.A.; Wong, C.H.; Sourial, N.; Chertkow, H. Dual-tasking and gait in people with mild cognitive impairment. The effect of working memory. BMC Geriatr. 2009, 9, 41. [CrossRef] 
8. Bridenbaugh, S.A.; Kressig, R.W. Laboratory review: The role of gfait analysis in seniors' mobility and fall prevention. Gerontology 2011, 57, 256-264. [CrossRef]

9. Weuve, J.; Kang, J.H.; Manson, J.A.E.; Breteler, M.M.B.; Ware, J.H.; Grodstein, F. Physical activity, including walking, and cognitive function in older women. J. Am. Med. Assoc. 2004, 292, 1454-1461. [CrossRef]

10. Alves, C.R.R.; Gualano, B.; Takao, P.P.; Avakian, P.; Fernandes, R.M.; Morine, D.; Takito, M.Y. Effects of acute physical exercise on executive functions: A comparison between aerobic and strength exercise. J. Sport Exerc. Psychol. 2012, 34, 539-549. [CrossRef]

11. Mavros, Y.; Gates, N.; Wilson, G.C.; Jain, N.; Meiklejohn, J.; Brodaty, H.; Wen, W.; Singh, N.; Baune, B.T.; Suo, C.; et al. Mediation of Cognitive Function Improvements by Strength Gains After Resistance Training in Older Adults with Mild Cognitive Impairment: Outcomes of the Study of Mental and Resistance Training. J. Am. Geriatr. Soc. 2017, 65, 550-559. [CrossRef]

12. Kramer, A.F.; Colcombe, S. Fitness Effects on the Cognitive Function of Older Adults: A Meta-Analytic Study-Revisited. Perspect. Psychol. Sci. 2018, 13, 213-217. [CrossRef]

13. Farina, N.; Rusted, J.; Tabet, N. The effect of exercise interventions on cognitive outcome in Alzheimer's disease: A systematic review. Int. Psychogeriatrics 2014, 26, 9-18. [CrossRef]

14. Hsu, C.L.; Best, J.R.; Davis, J.C.; Nagamatsu, L.S.; Wang, S.; Boyd, L.A.; Hsiung, G.R.; Voss, M.W.; Eng, J.J.; Liu-Ambrose, T. Aerobic exercise promotes executive functions and impacts functional neural activity among older adults with vascular cognitive impairment. Br. J. Sports Med. 2018, 52, 184-191. [CrossRef]

15. Bliss, E.S.; Wong, R.H.X.; Howe, P.R.C.; Mills, D.E. Benefits of exercise training on cerebrovascular and cognitive function in ageing. J. Cereb. Blood Flow Metab. 2021, 41, 447-470. [CrossRef]

16. Nagamatsu, L.S.; Chan, A.; Davis, J.C.; Beattie, B.L.; Graf, P.; Voss, M.W.; Sharma, D.; Liu-Ambrose, T. Physical activity improves verbal and spatial memory in older adults with probable mild cognitive impairment: A 6-month randomized controlled trial. $J$. Aging Res. 2013, 2013. [CrossRef]

17. Liu-Ambrose, T.; Nagamatsu, L.S.; Voss, M.W.; Khan, K.M.; Handy, T.C. Resistance training and functional plasticity of the aging brain: A 12-month randomized controlled trial. Neurobiol. Aging 2012, 33, 1690-1698. [CrossRef]

18. Vaughan, S.; Wallis, M.; Polit, D.; Steele, M.; Shum, D.; Morris, N. The effects of multimodal exercise on cognitive and physical functioning and brain-derived neurotrophic factor in older women: A randomised controlled trial. Age Ageing 2014, 43, 623-629. [CrossRef]

19. Fragala, M.S.; Beyer, K.S.; Jajtner, A.R.; Jeremy, R.; Pruna, G.J.; Boone, C.H.; Bohner, J.D.; Fukuda, D.H.; Stout, J.R.; Hoffman, J.R. Resistance exercise may improve spatial awareness and visual reaction in older adults. J. Strength Cond. Res. 2014, 28, $2079-2087$. [CrossRef]

20. Keating, C.J.; Cabrera-Linares, J.C.; Párraga-Montilla, J.A.; Latorre-Román, P.A.; del Castillo, R.M.; García-Pinillos, F. Influence of Resistance Training on Gait \& Balance Parameters in Older Adults: A Systematic Review. Int. J. Environ. Res. Public Health 2021, 18, 1759. [CrossRef]

21. Bouaziz, W.; Vogel, T.; Schmitt, E.; Kaltenbach, G.; Geny, B.; Lang, P.O. Health benefits of aerobic training programs in adults aged 70 and over: A systematic review. Arch. Gerontol. Geriatr. 2017, 69, 110-127. [CrossRef] [PubMed]

22. Taekema, D.G.; Gussekloo, J.; Maier, A.B.; Westendorp, R.G.J.; de Craen, A.J.M. Handgrip strength as a predictor of functional, psychological and social health. A prospective population-based study among the oldest old. Age Ageing 2010, 39, 331-337. [CrossRef] [PubMed]

23. Taekema, D.G.; Ling, C.H.Y.; Kurrle, S.E.; Cameron, I.D.; Meskers, C.G.M.; Blauw, G.J.; Westendorp, R.G.J.; De craen, A.J.M.; Maier, A.B. Temporal relationship between handgrip strength and cognitive performance in oldest old people. Age Ageing 2012, 41, 506-512. [CrossRef] [PubMed]

24. Burns, J.M.; Johnson, D.K.; Watts, A.; Swerdlow, R.H.; Brooks, W.M. Reduced lean mass in early Alzheimer disease and its association with brain atrophy. Arch. Neurol. 2010, 67, 428-433. [CrossRef]

25. Ling, C.H.Y.; Taekema, D.; De Craen, A.J.M.; Gussekloo, J.; Westendorp, R.G.J.; Maier, A.B. Handgrip strength and mortality in the oldest old population: The Leiden 85-plus study. Cmaj 2010, 182, 429-435. [CrossRef]

26. Cooper, R.; Kuh, D.; Hardy, R. Objectively measured physical capability levels and mortality: Systematic review and meta-analysis. BMJ 2010, 341, 639. [CrossRef]

27. Hertzog, C.; Kramer, A.F.; Wilson, R.S.; Lindenberger, U. Enrichment Effects on Adult Cognitive Development. Psychol. Sci. Public Interes. 2008, 9, 1-65. [CrossRef]

28. Bherer, L.; Erickson, K.I.; Liu-Ambrose, T. A review of the effects of physical activity and exercise on cognitive and brain functions in older adults. J. Aging Res. 2013, 2013. [CrossRef]

29. Aley, L.; Miller, E.W.; Bode, S.; Hall, L.; Markusic, J.; Nicholson, M.; Winegardner, M. Effects of age, task complexity, and exercise on reaction time of women during ambulation tasks. J. Geriatr. Phys. Ther. 2007, 30, 3-7. [CrossRef]

30. Pijnappels, M.; Delbaere, K.; Sturnieks, D.L.; Lord, S.R. The association between choice stepping reaction time and falls in older adults-a path analysis model. Age Ageing 2010, 39, 99-104. [CrossRef]

31. Senior fitness test manual. Choice Rev. Online 2002, 39, 39-3447. [CrossRef]

32. Innes, E. Handgrip strength testing: A review of the literature. Aust. Occup. Ther. J. 1999, 46, 120-140. [CrossRef]

33. Pedrero-Chamizo, R.; Albers, U.; Tobaruela, J.L.; Meléndez, A.; Castillo, M.J.; González-Gross, M. Physical strength is associated with Mini-Mental State Examination scores in Spanish institutionalized elderly. Geriatr. Gerontol. Int. 2013, 13, 1026-1034. [CrossRef] 
34. Lienhard, K.; Schneider, D.; Maffiuletti, N.A. Validity of the Optogait photoelectric system for the assessment of spatiotemporal gait parameters. Med. Eng. Phys. 2013, 35, 500-504. [CrossRef]

35. Stroop, J.R. Studies of interference in serial verbal reactions. J. Exp. Psychol. 1935, 18, 643-662. [CrossRef]

36. Golden, C.J. Test de Colores y Palabras (Stroop), 6th ed.; Ruiz-Fernández, B., Luque, T., Sánchez-Sánchez, F., Eds.; TEA Ediciones, S.A.U.: Madrid, Spain, 2020; ISBN 9788416231782.

37. Brickenkamp, R. d2, Test de Atención (adapt. Nicolás Seisdedos Cubero), 4th ed.; Cubero, N.S., Ed.; TEA Ediciones, S.A.U.: Madrid, Spain, 2012; ISBN 978-84-15262-68-8.

38. Reitan, R.M. Validity of the trail making test as an indicator of organic brain damage. Percept. Mot. Ski. 1958, 8, 271-276. [CrossRef]

39. Valencia Marín, C.M.; López Alzate, E.; Tirado Pérez, V.; Zea Herrera, M.; Lopera Restrepo, F.; Rupprecht, R.; Oswald, W.D. Efectos cognitivos de un entrenamiento combinado de memoria y psicomotricidad en adultos mayores. Rev. Neurol. 2008, 46, 465 . [CrossRef]

40. Fabre, C.; Chamari, K.; Mucci, P.; Massé-Biron, J.; Préfaut, C. Improvement of Cognitive Function by Mental and/or Individualized Aerobic Training in Healthy Elderly Subjects. Int. J. Sports Med. 2002, 23, 415-421. [CrossRef]

41. Bijlsma, A.Y.; Meskers, C.G.M.; Ling, C.H.Y.; Narici, M.; Kurrle, S.E.; Cameron, I.D.; Westendorp, R.G.J.; Maier, A.B. Defining sarcopenia: The impact of different diagnostic criteria on the prevalence of sarcopenia in a large middle aged cohort. Age 2013, 35, 871-881. [CrossRef]

42. Falbo, S.; Condello, G.; Capranica, L.; Forte, R.; Pesce, C. Effects of Physical-Cognitive Dual Task Training on Executive Function and Gait Performance in Older Adults: A Randomized Controlled Trial. Biomed Res. Int. 2016, 2016. [CrossRef]

43. Plummer, P.; Zukowski, L.A.; Giuliani, C.; Hall, A.M.; Zurakowski, D. Effects of Physical Exercise Interventions on Gait-Related Dual-Task Interference in Older Adults: A Systematic Review and Meta-Analysis. Gerontology 2015, 62, 94-117. [CrossRef] 